7. Child Lang. 28 (2001), 373-391. Printed in the United Kingdom

(C) 200I Cambridge University Press

\title{
Form and function of negation in early developmental Cantonese*
}

\author{
CLARA W-Y. TAM AND STEPHANIE F. STOKES \\ University of Hong Kong \\ (Received I9 October 1998. Revised 10 April 2000)
}

\begin{abstract}
This study investigated the interface of form and function in the acquisition of negation in Cantonese-speaking children. The data, from the Hong Kong Cantonese Child Language Corpus, were longitudinal spontaneous samples of eight children aged $\mathrm{I} ; 5$ to $3 ; 8$. The main issues of the study were the sequence of emergence of negative markers $\operatorname{mou}_{5}$, $m_{4}$ and $m e i_{6}$ and the acquisition trend of $\mathrm{I}$ I semantic categories of negation in children's expressive language. The acquisition trend of the semantic categories matched Bloom's ( r970, I991a) finding that Nonexistence preceded Rejection and Denial.
\end{abstract}

\section{INTRODUCTION}

Acquisition of negation in children was a popular topic of investigation in the I 960 s and I970s when researchers reported on the form and function of negation in several languages, for example English (Bloom, I970) Japanese (McNeill \& McNeill, I 968), Finnish (Bowerman, I973) and German (Wode, I976; Park, I979). At that time, the research focus was on the semantic diversity of lexemes encoding negation and the syntactic frames in which negation occurred. Subsequently, similar frameworks were applied to Mandarin and Tamil (T. Lee, I982; Vaidyanathan, I99I) and, in a crosslinguistic study, to French, English and Korean (Choi, I 988). More recently, discourse paradigms have been applied to old questions to explain the syntactic location and semantics of negative markers in English. For example, Drozd (I995) espoused a metalinguistic explanation of English children's use of nonanaphoric pre-sentential negation. The general trend in investigations of developmental negation has been an examination of the form/function interface across development, followed by elucidation of the

[*] Many thanks to Paul Fletcher for comments on a draft of this manuscript, and to Dr Zehava Weisman and her research assistants for their help in using the CHAT files. Address for correspondence: Dr S. F. Stokes, Department of Speech and Hearing Sciences, University of Hong Kong, 5/F, 34 Hospital Road, Hong Kong, SAR, China. e-mail: sstokes@hkusua.hku.hk 
syntactic contexts of negation in children's language. Here we briefly review the findings on the interface of form and function, before exploring this interface in Cantonese, a dialect of Chinese.

A general conclusion from studies of developmental sentence negation is that the semantic categories of negation are learnt in the sequence of nonexistence $>$ rejection $>$ denial, as described by Bloom (I970, I99 Ia) for children aged between $1 ; 6$ and 2; 1 . Despite the employment of a range of semantic categories, this general trend can be distilled from most studies, for a range of languages. For example, in a case study of the development of Japanese, McNeill \& McNeill (ig68) found three semantic categories of negation, i.e. nonexistence, lack of internal desire and nonentailing denial (coded by the authors as Existence-Truth, Internal-External, and Entailment-Non-entailment), which Bloom (I970, I991a) interpreted as basically equivalent to nonexistence, rejection, and denial. The same general result is believed to hold for Tamil, once the confound of including negation at the single word stage of development is removed (Bloom, I99 r b). When the confound is included, the order of development of Tamil negation is rejection $>$ non-existence $>$ prohibition $>$ denial, for children aged $0 ; 9$ to 2;9 (Vaidyanathan, I 99I). As the age range under investigation increases, so too does the range of semantic categories and the likelihood of individual variability. In a cross-linguistic study of French, English and Korean, the order of emergence of negation was reported as Phase $\mathrm{I}$ : (nonexistence), prohibition, rejection, (failure) $>$ Phase 2 : denial, (inability, epistemic negation) $>$ Phase 3 : normative negation, inferential negation, where brackets indicate that some children used these categories at the given stage, while other children used them in the next stage (Choi, I988).

T. Lee (1982) studied the development of negation in a Mandarinspeaking child aged I; 5 to I; II. His nine semantic categories were nonexistence of object, nonrecurrence of object, negative volition, negative imperative, denial of object identity, nonoccurrence of event, nonrecurrence of event, nonexistence of state or quality of object and inability. Lee found a trend for Mandarin that was slightly different from that suggested for other languages, viz a trend of rejection $>$ nonexistence $>$ denial. Given the generally universal trend of nonexistence $>$ rejection $>$ denial, and the slightly different findings for Mandarin, we investigated which direction the development of Cantonese would follow. In line with previous work, it would be instructive to know how the form/function interface changes over time for Cantonese.

\section{Cantonese}

There are four markers of negation in Cantonese; they are $\operatorname{mou}_{5}, m_{4}$, $m a i_{2} / m a i_{5} / m a i_{6}$ and $m e i_{6}$. (The numbers are used to mark Cantonese tones as follows: $\mathrm{I}=$ high level, $2=$ high rising, $3=$ mid level, $4=$ low falling, $5=$ 
low rising, $6=$ low level.) These four markers have their own features. For example, $\operatorname{mou}_{5}$ is the antonym of $j a u_{5}$ (have), meaning have not. The form $m_{4}$ means not and is used as a prefix for words from certain categories (verbs, adjectives and some adverbs), according to Yip (I988) to form various negative words, e.g. $m_{4} h_{0}$ (not good), $m_{4}$ leng $_{3}$ (not beautiful). The form mai can be pronounced as tone 2,5 or 6 , all of which carry a negative meaning in Cantonese. When it is pronounced as tone 2 and 5 , it also carries an imperative meaning, don't, while in tone 6 , it serves as a marker in a question, e.g. A-not-A questions and yes/no question. Lastly, the form $m e i_{6}$ means not yet or not complete. Most of these negative markers are of low tone, that is, tone 4,5 or 6 , with the exception of mai $_{2}$ (Matthews \& Yip, I994).

The main issues of this study are the developmental order of negative markers $m o u_{5}, m_{4}, m a i_{2} / m a i_{5} / m a i_{6}$ and $m e i_{6}$ and the semantic acquisition trend of negation. Furthermore, the intersection of those negative markers and semantic categories will be explored, because when each negative marker combines with different morphemes or within a specific context, the semantics of negation vary. Therefore, each negative marker can carry more than one meaning.

METHOD

Data

Data came from The Hong Kong Cantonese Child Language Corpus (Lee, Wong, Leung, Man, Cheung, Szeto \& Wong, I 994). The database contains longitudinal data on the spontaneous language of eight children (four males and four females). The children were visited at their homes, approximately

twice per month, for about one year, generating I7 I data files. The data consisted of adult-child conversation during daily activities. The average sampling time was one hour. The youngest child was I ; 5 and the oldest 2;8 when recording began, resulting in samples from $\mathrm{I} ; 5$ to $3 ; 8$ years. Table $\mathrm{I}$ shows the background information of the eight children.

\section{Stages for analysis}

The transcriptions were typed into CHAT computer files in the format of the Child Language Exchange System (CHILDES) project. The MLU of the first roo utterances of all computer files was calculated by the CLAN programmes. The MLU of all files in the corpus was between I.I 25 and 4. I 70. Bloom's ( i 970) analysis of developmental negation was based on data from three children, with MLUs between $I^{\prime}{ }^{\prime} 9$ and $2 \cdot 83$. To allow comparison with Bloom's findings, we selected files that had comparable MLUs, from I.360 to $2 \cdot 960$. By plotting the distribution of MLU, four stages of development were identified. The first stage was $\mathrm{r}_{3} 360-\mathrm{I}_{5} 60$, followed by a gap of $0 \cdot 2 \mathrm{MLU}$, giving Stage II an MLU of $r^{\cdot} 760-{ }^{\circ} \cdot 960$. Stage III covered 
TAM \& STOKES

TABLE I. Background information of the children

\begin{tabular}{|c|c|c|c|c|}
\hline Name & Sex & $\begin{array}{l}\text { Age at which } \\
\text { recording began } \\
\text { and ended }\end{array}$ & Language(s) used at home & Sibling \\
\hline WBH & $\mathrm{F}$ & $2 ; 3.23-3 ; 4.8$ & Cantonese & I younger brother \\
\hline CGK & $\mathrm{F}$ & I ; I I . I-2; 9.9 & Cantonese & - \\
\hline MHZ & M & I $; 7.0-2 ; 8.6$ & Cantonese & - \\
\hline CKT & M & $\mathrm{I} ; 5.22-2 ; 7.22$ & $\begin{array}{l}\text { Cantonese, parents occasionally } \\
\text { introduce English terms to the } \\
\text { child }\end{array}$ & - \\
\hline LTF & $\mathrm{F}$ & $2 ; 2.10-3 ; 2.18$ & $\begin{array}{l}\text { Cantonese except when speaking } \\
\text { to the Filipino helper }\end{array}$ & I elder sister \\
\hline $\mathrm{HHC}$ & M & $2 ; 4.8-3 ; 4.14$ & $\begin{array}{l}\text { Cantonese, Filipino helper speaks } \\
\text { some Cantonese \& English to the } \\
\text { child }\end{array}$ & $\begin{array}{l}\text { I elder brother } \& \\
\text { I elder sister }\end{array}$ \\
\hline LLY & $\mathrm{F}$ & $2 ; 8.10-3 ; 8.9$ & $\begin{array}{l}\text { Cantonese, family employs a Thai } \\
\text { helper who speaks Cantonese to } \\
\text { the child }\end{array}$ & I elder sister \\
\hline $\mathrm{CCC}$ & M & I; 10.8-2; 10.27 & & - \\
\hline
\end{tabular}

TABLE 2. MLU and number of files of the four stages

\begin{tabular}{|c|c|c|c|}
\hline Stage & MLU & Number of files & $\begin{array}{l}\text { Age (months) } \\
\text { mean (and s.D.) }\end{array}$ \\
\hline I & $I \cdot 36-I \cdot 56$ & $2 \mathrm{I}$ & $\begin{array}{c}24 \\
(2 \cdot 9)\end{array}$ \\
\hline II & $I \cdot 76-I \cdot 96$ & I7 & $\begin{array}{c}28 \\
(3 \cdot 3)\end{array}$ \\
\hline III & $2 \cdot 2 \mathrm{I}-2 \cdot 4 \mathrm{I}$ & I 8 & $\begin{array}{c}3 \mathrm{I} \\
(5 \cdot \mathrm{I})\end{array}$ \\
\hline IV & $2 \cdot 76-2 \cdot 96$ & I 4 & $\begin{array}{c}35 \\
(4 \cdot I)\end{array}$ \\
\hline
\end{tabular}

the range 2.2 I to 2.4I (a step up of $0.25 \mathrm{MLU}$ ), and Stage IV covered the range $2 \cdot 76-2 \cdot 96$ (a step up of $0.35 \mathrm{MLU}$ ). Table 2 shows the stages and MLUs for the selected 70 files and the mean ages of the children per stage.

Rules for negative utterance selection

The following rules were used to select negative utterances from the corpus.

Utterances including negative markers AND carrying a negative semantic role were included in the analysis. (According to Lahey (I988), negation is coded only if the child's utterance involved an overt negative marker.)

Include only complete utterances, including single words mou $_{5}$, $\mathrm{mai}_{2} / \mathrm{mai}_{5} / \mathrm{mai}_{6}$ as elliptical expressions are very common in Cantonese but 
accept the single nasal $m_{4}$ only where it occurs as a prefix, for example $m_{4} h o u_{2}$ (not good), as $m_{4}$ cannot stand alone.

Exclude utterances involving a negative marker that does not carry a negative semantic role. In Cantonese, it is common to find negative markers in question forms, such as A-not-A question, for example

I. nei $_{5} \quad \operatorname{sik}_{6} \mathrm{~m}_{4} \quad \mathrm{sik}_{6} \quad$ beng $_{2} \quad \mathrm{aa}_{3}$ ?

You eat not eat biscuit sentence final particle

do you want to eat a biscuit?

and yes-no questions

2. yauh $_{5} \operatorname{mou}_{5} \mathrm{jam}_{2}$ have not drink

do you have a drink?

However, these questions do not carry a negative meaning.

Exclude non-verbal expressions (e.g. head-shaking by the child).

Exclude mazes, false starts, repetitions, or reformulations in an utterance (Miller \& Chapman, I 993).

Exclude utterances with unintelligible words.

Exclude children's repeated utterances because repeated utterances would carry the same semantic meaning as the previous utterance.

Example: The mother asks the child to drink milk

3. Child: $\mathrm{m}_{4}$ jam $_{2}$

not drink

$\mathrm{m}_{4}$ jam $_{2}$

not drink

Repeated utterances that were probed by the listener.

Example: The child wanted to search for his comb

4. Child: $\mathrm{m}_{4} \operatorname{gin}_{3} \mathrm{zo}_{2}$

not see aspect marker

lost it

Investigator: lei ${ }_{5}$ soeng wan $_{2} \quad \mathrm{me}_{1} \mathrm{aa}_{3}$

You want search for what sentence final particle

What do you want to search for?

Child: $\mathrm{m}_{4} \quad \operatorname{gin}_{3} \mathrm{zo}_{2}$

not see aspect marker

lost it

Semantic analysis

In this study, the analysis of semantic categories of negation was initially based on T. Lee's (1982) classification for Mandarin because this classification of semantics was sufficiently detailed to capture the range of 
TA BLE 3. Definition and example of semantic categories ( $1-9$ adapted from T. Lee, I982)

\begin{tabular}{|c|c|c|}
\hline Semantic categories & Definition & Examples \\
\hline \multicolumn{3}{|l|}{ Nonexistence } \\
\hline Nonexistence of object & $\begin{array}{l}\text { The speaker expects the existence of an object, animate or } \\
\text { inanimate, at a certain place; or the speaker believes that } \\
\text { the listener has suggested in a previous utterance the } \\
\text { existence of the object. }\end{array}$ & $\begin{aligned} \text { Inv: } & \mathrm{jau}_{5} \mathrm{mou}_{5} \mathrm{ap}_{2} \\
& \text { have not duck? } \\
& \text { Is there any duck? } \\
\text { Chi: } & \text { mou }_{5} \\
& \text { have not } \\
& \text { no }\end{aligned}$ \\
\hline Nonrecurrence of object & $\begin{array}{l}\text { The speaker expects the reappearance of an object (whose } \\
\text { existence has been perceived by the speaker prior to } \\
\text { the negation), or of another object of a similar kind. }\end{array}$ & $\begin{array}{l}\text { The child finishes all the chips in his hand } \\
\text { Chi: } \text { mou }_{5} \\
\text { have not } \\
\text { all gone }\end{array}$ \\
\hline Nonoccurrence of event & $\begin{array}{l}\text { The speaker expects the occurrence of an event at a } \\
\text { certain time and place; or the speaker believes that the } \\
\text { listener has suggested in a previous utterance the } \\
\text { occurrence of an event. }\end{array}$ & $\begin{array}{l}\text { Chi: } \mathrm{ba}_{4} \mathrm{ba}_{1} \mathrm{mou}_{5} \mathrm{dai}_{3} \mathrm{ce}_{1} \\
\text { Father have not bring umbrella } \\
\text { Father has not brought an umbrella }\end{array}$ \\
\hline Nonrecurrence of event & $\begin{array}{l}\text { The speaker expects a continuation of an event whose } \\
\text { occurrence he has perceived. }\end{array}$ & $\begin{array}{l}\text { The tape recorder stops } \\
\text { Chi: } \mathrm{m}_{4} \mathrm{juk}_{1} \\
\text { not move } \\
\text { doesn't move }\end{array}$ \\
\hline $\begin{array}{l}\text { Nonexistence of state } \\
\text { or quality of object }\end{array}$ & $\begin{array}{l}\text { The speaker expects to find an object in a certain state or } \\
\text { possessing a certain quality; or the speaker believes that } \\
\text { the listener has suggested in a previous utterance that the } \\
\text { object may be in a certain state or possess a certain quality. }\end{array}$ & $\begin{array}{l}\text { Chi: } \mathrm{m}_{4} \text { tung }_{3} \\
\text { not pain } \\
\text { (I'm) not hurt }\end{array}$ \\
\hline \multicolumn{3}{|l|}{ Rejection } \\
\hline Negative volition & $\begin{array}{l}\text { The speaker assumes that the listener wants to impose an } \\
\text { object or an action on him; this assumption stems from } \\
\text { the child's own perception of the situation, or from a } \\
\text { verbal suggestion in a previous utterance of the listener. }\end{array}$ & $\begin{array}{l}\text { The investigator asks the child if she } \\
\text { would like to read a book. } \\
\text { Inv: soeng }{ }_{2} \mathrm{~m}_{4} \text { soeng }{ }_{2} \text { tai }{ }_{2} \mathrm{sy}_{1} \\
\text { Want not want see book } \\
\text { Do you want to read book? } \\
\text { Chi: } \mathrm{m}_{4} \text { soeng } \\
\text { not want } \\
\text { no (I) don't want to } \\
\text { don't read }\end{array}$ \\
\hline
\end{tabular}


Negative imperative

\section{Denial}

Denial of object identity

Inability

ป้ Denial of happening of event

Denial of object function

The speaker believes the function of an object; or the speaker believes that the listener has suggested in a previous utterance the function of the object.
The speaker believes that the listener is carrying out or about to carry out an action. In this case, the action

intended or carried out is not directed toward the speaker.

The speaker assumes that the listener has suggested in previous utterance that the name of an object is $\mathrm{X}$.

The speaker believes that he may be able to perform a certain physical or mental task.

The speaker denial denies the happening of an event that has happened.
The mother wants to read the story book

Chi: $\mathrm{m}_{4}$ bei $_{2}$ not allow

don't read (the book)

The investigator holds a taxi

Inv: hai $_{6} \mathrm{~m}_{4} \mathrm{hai}_{6} \mathrm{ba}_{1} \mathrm{si}_{2}$ ?

be not be bus?

Is this a bus?

Chi: $\mathrm{m}_{4}$ hai $_{6}$

not

The child cannot reach for the toy that on the shelf.

Chi: $\mathrm{lo}_{2} \mathrm{~m}_{4}$ tou $_{2}$

take not can

can't reach it

The child is drooling

Inv: $\mathrm{lau}_{4} \mathrm{hau}_{2}$ soei $_{2}$

flow mouth water

(you're) drooling

Chi: mou

have not

$$
\text { I'm not }
$$

The investigator points to a cooking spatula

Inv: hai $_{6} \mathrm{~m}_{4}$ hai $_{6}$ jung $_{6}$ lai $_{4} \mathrm{da}_{2} \mathrm{bo}_{1}$ Be not be used for play ball? Is this used for playing ball?

Chi: $\mathrm{m}_{4}$ hai $_{6}$ jung $_{6}$ lai $_{4} \mathrm{zy}_{2} \mathrm{je}_{6}$ sik $_{6}$ Not be, used for cook thing eat no, it's used for cooking

things to eat

Inv, investigator; Chi, child. 
meanings in Cantonese. Also, Mandarin shares linguistic characteristics with Cantonese. According to T. Lee's ( 1982 ) classification system there are nine semantic categories: nonexistence of object, nonrecurrence of object, negative volition, negative imperative, denial of object identity, nonoccurrence of event, nonrecurrence of event, nonexistence of state or quality of object and inability. Other than these nine categories, two more semantic categories are proposed by the authors: denial of happening of event and denial of object function. These categories were added because there were instances in the conversations where it was clear that the child was expressing additional categories of denial. For example, when the adult stated that the child was drooling, saying

5. $\mathrm{lau}_{4} \mathrm{hau}_{2} \mathrm{soei}_{2}$ flow mouth water (you're) drooling

the child denied the event, replying ' mou $_{5}$ ' (not). A further category was shown in denial of the adult's suggested use of an object. For example, in one sample the adult showed the child a cooking spatula and asked

6. hai $_{6} \mathrm{~m}_{4}$ hai $_{6}$ jung $_{6}$ lai $_{4}$ da $_{2}$ bo $_{1}$ be not be use for play ball is this for playing ball?

to which the child replied

7. $\mathrm{m}_{4}$ hai $_{6}$ jung $_{5} \quad$ lai $_{4} \mathrm{zy}_{2} \quad \mathrm{je}_{5} \quad \mathrm{sik}_{6}$ not be use for cook thing eat no, it's used for cooking things to eat

The definitions and examples of these semantic categories are shown in Table 3. To facilitate comparison with the development of English, these categories were then collapsed into three commonly used categories (Bloom, i99ia), which capture the main semantic sense of each category, that is nonexistence (nonexistence of object, nonrecurrence of object, nonocurrence of event, nonrecurrence of event and nonexistence of state or quality of object), rejection (negative volition and negative imperative), and denial (denial of object identity, inability, denial of happening of event and denial of object function).

To ensure the reliability of the analysis, intra- and inter-rater reliability was determined. Ten percent of all utterances were re-coded by the first author and a point-by-point comparison was made with a second coder. The agreements of both inter- and intra-rater reliability measures were over $90 \%$. The remaining disagreements were resolved to ensure the accuracy of analysis. 
TABLE 4. Lexical markers and the semantic categories they encode at each stage of development for each child.

\begin{tabular}{|c|c|c|c|c|c|c|c|c|c|c|c|c|}
\hline \multirow[b]{3}{*}{ Child } & \multicolumn{12}{|c|}{ Stage } \\
\hline & \multicolumn{3}{|c|}{ I } & \multicolumn{3}{|c|}{ II } & \multicolumn{3}{|c|}{ III } & \multicolumn{3}{|c|}{ IV } \\
\hline & $\mathrm{NE}$ & Rej & Den & $\mathrm{NE}$ & Rej & Den & $\mathrm{NE}$ & Rej & Den & $\mathrm{NE}$ & Rej & Den \\
\hline $\mathrm{CCC}$ & $\begin{array}{c}\mathrm{mou}_{5} \\
\mathrm{~m}_{4}\end{array}$ & $\mathrm{~m}_{4}$ & $\mathrm{~m}_{4}$ & & & & $\mathrm{mou}_{5}$ & $\mathrm{mou}_{5}$ & $\mathrm{~m}_{4}$ & & & \\
\hline CGK & & & & $\begin{array}{c}\mathrm{mou}_{5} \\
\mathrm{~m}_{4}\end{array}$ & $\mathrm{~m}_{4}$ & $\mathrm{~m}_{4}$ & $\begin{array}{c}\mathrm{mou}_{6} \\
\mathrm{~m}_{4}\end{array}$ & $\mathrm{~m}_{4}$ & $\mathrm{~m}_{4}$ & $\underset{\mathrm{mou}_{5}}{\mathrm{mou}_{4}}$ & $\mathrm{~m}_{4}$ & $\begin{array}{c}\mathrm{mou}_{5} \\
\mathrm{~m}_{4}\end{array}$ \\
\hline CKT & $\begin{array}{c}\mathrm{mou}_{5} \\
\mathrm{~m}_{4}\end{array}$ & & & $\begin{array}{c}\mathrm{mou}_{5} \\
\mathrm{~m}_{4} \\
\mathrm{mei}_{6}\end{array}$ & $\mathrm{mou}_{5}$ & $\mathrm{~m}_{4}$ & & & & & & \\
\hline $\mathrm{HHC}$ & $\mathrm{mou}_{5}$ & $\begin{array}{c}\mathrm{mou}_{5} \\
\mathrm{~m}_{4}\end{array}$ & & & & & $\begin{array}{c}\mathrm{mou}_{5} \\
\mathrm{~m}_{4} \\
\mathrm{mei}_{6}\end{array}$ & $\begin{array}{c}\mathrm{mou}_{5} \\
\mathrm{~m}_{4}\end{array}$ & & $\begin{array}{c}\mathrm{mou}_{5} \\
\mathrm{~m}_{4} \\
\mathrm{mei}_{6}\end{array}$ & $\begin{array}{c}\mathrm{mou}_{5} \\
\mathrm{~m}_{4}\end{array}$ & $\mathrm{~m}_{4}$ \\
\hline LLY & & & & $\begin{array}{c}\mathrm{mou}_{5} \\
\mathrm{~m}_{4} \\
\mathrm{mei}_{6}\end{array}$ & $\begin{array}{c}\mathrm{mou}_{5} \\
\mathrm{~m}_{4} \\
\mathrm{mei}_{6}\end{array}$ & $\mathrm{~m}_{4}$ & $\begin{array}{c}\mathrm{mou}_{5} \\
\mathrm{~m}_{4} \\
\mathrm{mei}_{6}\end{array}$ & $\begin{array}{c}\mathrm{mou}_{5} \\
\mathrm{~m}_{4}\end{array}$ & $\mathrm{~m}_{4}$ & $\begin{array}{c}\mathrm{mou}_{5} \\
\mathrm{~m}_{4} \\
\mathrm{mei}_{6}\end{array}$ & $\mathrm{~m}_{4}$ & $\underset{\mathrm{m}_{4}}{\mathrm{mou}_{5}}$ \\
\hline LTF & & & & $\underset{\mathrm{m}_{4}}{\mathrm{mou}_{5}}$ & $\mathrm{~m}_{4}$ & $\mathrm{~m}_{4}$ & $\begin{array}{c}\mathrm{mou}_{5} \\
\mathrm{~m}_{4} \\
\mathrm{mei}_{6}\end{array}$ & $\mathrm{~m}_{4}$ & $\begin{array}{c}\mathrm{mou}_{5} \\
\mathrm{~m}_{4}\end{array}$ & & & \\
\hline MHZ & $\begin{array}{c}\mathrm{mou}_{5} \\
\mathrm{~m}_{4}\end{array}$ & $\mathrm{mou}_{5}$ & $\mathrm{~m}_{4}$ & $\begin{array}{c}\mathrm{mou}_{5} \\
\mathrm{~m}_{4} \\
\mathrm{mei}_{6}\end{array}$ & $\begin{array}{c}\mathrm{mou}_{5} \\
\mathrm{~m}_{4}\end{array}$ & $\begin{array}{c}\mathrm{m}_{4} \\
\mathrm{mei}_{6}\end{array}$ & $\mathrm{mou}_{5}$ & $\mathrm{~m}_{4}$ & $\mathrm{~m}_{4}$ & $\underset{\mathrm{m}_{4}}{\mathrm{mou}_{5}}$ & $\mathrm{~m}_{4}$ & $\mathrm{~m}_{4}$ \\
\hline WBH & $\mathrm{mou}_{5}$ & $\mathrm{~m}_{4}$ & & $\mathrm{~m}_{4}$ & $\mathrm{~m}_{4}$ & $\mathrm{~m}_{4}$ & $\begin{array}{c}\mathrm{mou}_{5} \\
\mathrm{~m}_{4} \\
\mathrm{mei}_{6}\end{array}$ & $\mathrm{~m}_{4}$ & $\mathrm{~m}_{4}$ & $\begin{array}{c}\mathrm{mou}_{5} \\
\mathrm{~m}_{4} \\
\mathrm{mei}_{6}\end{array}$ & $\mathrm{~m}_{4}$ & $\mathrm{~m}_{4}$ \\
\hline
\end{tabular}

NE, Nonexistence; Rej, Rejection; Den, Denial; I, Stage I; II, Stage II ; III, Stage III; IV, Stage IV; subscript indicates tone marker.

RESULTS

The 70 CHAT files of all eight children's data contained a total of 27530 utterances and a total of 2684 negative utterances. The form $m_{4}$ was the most common negative marker in the children's utterances. The form $m_{0} u_{5}$ was the second most common negative marker and the third most frequent form was $m e i_{6}$. The forms $m a i_{2}, m a i_{5}$ and $m a i_{6}$ were not commonly found in the data. This is because the most frequent use of these three markers is in the form of yes/no questions and tag questions, so they do not carry a negative meaning. All of these questions were not included in the data analysis. The form $\mathrm{mai}_{5}$ occurred once for the meaning of negative imperative, which is not sufficiently representative for inclusion in the analysis. Therefore, the study focused on the forms $m_{0} u_{5}, m_{4}$ and $m e i_{6}$. Developmental order of the form of negation is reported first, followed by the functions. 
Sequence of emergence of negative markers (form)

The negatives mou $_{5}$ and $m_{4}$ were already in use at the beginning of the sampling period, with $m e i_{6}$ emerging in Stages II-III. As not all children fell into each sampling stage, we can only estimate the stage of emergence of $m e i_{6}$. For example, of the six children with Stage II data, three used $m e i_{6}$ at Stage II (CKT, LLY and MHZ) and two children who had data at Stages II and III first used $m e i_{6}$ at Stage III (LTF and WBH). Two children who did not have Stage II data showed use of $m e i_{6}$ at Stage III (CCC and HHC) and the remaining child did not use $m e i_{6}$ at all throughout the sampling period (CGK). (See Table 4.)

\section{Distribution of semantic categories (content)}

Frequency of use of each semantic category for each stage of development (group data) is shown in Table 5. The first row under the headings

TABLE 5. Percentage of occurrence of semantic categories across stages and for the total sample of negative utterances.

\begin{tabular}{|c|c|c|c|c|c|}
\hline \multirow[b]{2}{*}{ Semantic category } & \multicolumn{4}{|c|}{ Stage of development } & \multirow[b]{2}{*}{ Total } \\
\hline & I & II & III & IV & \\
\hline \multicolumn{6}{|l|}{ Nonexistence } \\
\hline Number & 2 II & 332 & 369 & 238 & I I 50 \\
\hline Percentage of Stage & 48 & 43 & $4 \mathrm{I}$ & 43 & \\
\hline Percentage of Database & 7 & 12 & I4 & 9 & 43 \\
\hline \multicolumn{6}{|l|}{ Rejection } \\
\hline Number & I 86 & 267 & 236 & I 68 & 857 \\
\hline Percentage of Stage & 43 & 34 & 26 & 30 & \\
\hline Percentage of Database & 7 & Io & 9 & 6 & 32 \\
\hline \multicolumn{6}{|l|}{ Denial } \\
\hline Number & 37 & I 78 & 297 & I 53 & 665 \\
\hline Percentage of Stage & 8 & 23 & 33 & 27 & \\
\hline Percentage of Database & I & 7 & I I & 6 & 25 \\
\hline Unanalysed (number) & I & 7 & I & 3 & $\mathrm{I} 2$ \\
\hline Total & 435 & 784 & 903 & 562 & 2684 \\
\hline Percentage of stage & 100 & 100 & 100 & 100 & \\
\hline Percentage of database & $\mathrm{I}_{5}$ & 29 & 34 & $2 \mathrm{I}$ & \\
\hline
\end{tabular}

Nonexistence, Rejection and Denial shows the number of occurrences of these categories within each stage of development. The second row shows the relative frequency of occurrence of the categories. For example, at Stage I, Nonexistence $=48$ means that $48 \%$ of all negations at Stage I were Nonexistence. The early use of Nonexistence and Rejection is seen in the percentage of use of these categories at Stage I 
( $48 \%$ and $43 \%$ respectively), relative to that for Denial $(8 \%)$. This relationship changes over time as Denial was used more frequently to encode negation as language ability increased. At Stage II the relative frequency for Nonexistence, Rejection and Denial was $43 \%, 34 \%$ and $23 \%$; at Stage III it was $4 \mathrm{I} \%, 26 \%$ and $33 \%$; at Stage IV it was $43 \%, 30 \%$ and $27 \%$. As is reflected by these percentages, the use of Nonexistence remained constant as an expression of negation, whereas Rejection decreased from $43 \%$ of Stage I negation to $30 \%$ of Stage IV negation as the use of Denial increased from $8 \%$ of all negative utterances at Stage I to $27 \%$ at Stage IV.

In terms of the proportion of the whole negation database, Nonexistence comprised $43 \%$ of all of the 2,684 negative utterances expressed throughout the sampling period, as shown in the Totals column of Table 5. Rejection comprised $32 \%$ of all negative utterances, and Denial $25 \%$. Negation was encoded most frequently in Stage III of development (Stage I $=435$ negative utterances, Stage II $=784$, Stage III $=903$ and Stage IV = 562). Although these data provide an overview of group performance, these results do not show which of the subordinate categories were used within these superordinate categories of Nonexistence, Rejection and Denial.

\section{General patterns of development of the subordinate categories}

Recall that within the three superordinate categories of negation, Nonexistence, Rejection and Denial, there were five subordinate categories for Nonexistence (nonexistence of object, nonrecurrence of object, nonoccurrence of event, nonrecurrence of event and nonexistence of state or quality of object), two for Rejection (negative volition and negative imperative) and four for Denial (denial of object identity, inability, denial of happening of event and denial of object function). Table 6 shows the

T A В LE 6. Percentage of children using each subordinate semantic category at each stage of development

\begin{tabular}{|c|c|c|c|c|c|c|c|c|c|c|c|}
\hline \multirow{3}{*}{ Stage } & \multicolumn{11}{|c|}{ Semantic categories } \\
\hline & \multicolumn{4}{|c|}{ Nonexistence } & \multicolumn{4}{|c|}{ Rejection } & \multicolumn{3}{|c|}{ Denial } \\
\hline & I & 2 & 3 & 4 & 5 & 6 & 7 & 8 & 9 & IO & I I \\
\hline $\mathrm{I}(\mathrm{n}=5)$ & IO० & 80 & 60 & o & 80 & IOO & I 00 & 60 & 60 & 20 & ○ \\
\hline II $(n=6)$ & 83 & 83 & IOO & 33 & $8_{3}$ & IOO & 83 & 83 & 83 & 66 & I 6 \\
\hline III $(\mathrm{n}=7)$ & IOO & 88 & IOO & I 4 & 88 & IO० & 88 & 88 & 88 & 66 & 28 \\
\hline IV $(n=5)$ & IO० & 80 & IOO & 66 & 80 & IO० & I0० & IO० & IOO & 66 & 40 \\
\hline
\end{tabular}

I, nonexistence of object; 2, nonrecurrence of object; 3 , nonoccurrence of event; 4 , nonrecurrence of event; 5 , nonexistence of state or quality of object; 6 , negative volition; 7 , negative imperative; 8 , denial of object identity; 9 , inability; ro, denial of happening of event; I I, denial of object function. I, Stage I; II, Stage II; III, Stage III; IV, Stage IV. 
percentage of children using each subordinate semantic category at each developmental stage (Stages I to IV). The number of children using each of these subordinate categories increased across the developmental period from Stage I to Stage IV. Particularly noteworthy was the increase in the proportion of children encoding 'nonrecurrence of event' (\#4) from $\circ \%$ at Stage I to $66 \%$ at Stage IV, 'denial of object identity (\#8) from $60 \%$ to г $00 \%$, 'inability' (\#9) from $60 \%$ to $100 \%$, and 'denial of object function' (\#II) from $0 \%$ to $40 \%$. Of interest is how these differences pattern as a function of stage of development.

Nonexistence. At Stage I, while all subjects encoded the superordinate category Nonexistence, the expression of subordinate categories varied across subjects. That is, while all five subjects expressed 'nonexistence of object', all except WBH also expressed 'nonrecurrence of object' and 'nonexistence of state or quality of object'. Three of the five children encoded 'nonoccurrence of event' (CKT, HHC and MHZ) but none of the children encoded 'nonrecurrence of event'. At Stage II, WBH continued to encode very few categories of negation, adding only 'nonrecurrence of object' and 'nonoccurrence of event'. Unlike WBH, all other subjects sampled at this stage $(n=6)$ encoded 'nonexistence of object' and 'nonexistence of state or quality of object' and two subjects expressed 'nonrecurrence of event' (LLY and LTF). This is the first use of 'nonrecurrence of event' among the children.

At Stage III WBH began to mark all but one of the categories of Nonexistence, the one not encoded was 'nonrecurrence of event' which at this stage of development was encoded only by CCC. By stage III all children encoded almost all of the categories of Nonexistence, except that there was no record of CGK using 'nonrecurrence of object' or 'nonexistence of state or quality of object'. By Stage IV MHZ and WBH still had not encoded 'nonrecurrence of event', but encoded all other categories of Nonexistence, as did every other subject.

Rejection. The percentage of children encoding Rejection remained steady across the four stages, with all children encoding this category at all stages, however, as with Nonexistence, WBH showed the weakest encoding of negation, and did not encode the subordinate category 'negative imperative' in Stages II and III, but used it 24 times at Stage IV.

Denial. At Stage I only CCC, CKT and MHZ encoded Denial, and these took the forms of 'denial of object identity' and 'denial of ability', with MHZ also encoding 'denial of object function'. At Stage II WBH was again the weakest, encoding only 'denial of happening of event', as did CKT, LLY and MHZ. All subjects except WBH encoded 'denial of object identity' and 'inability' and only LLY encoded 'denial of object function'. At Stage III HHC (also sampled at Stage I) still had not encoded Denial. All other subjects encoded 'denial of object identity' and 'inability', CCC, LLY, LTF 
and WBH encoded 'denial of happening of event' and only LTF and WBH encoded 'denial of object function'. At Stage IV, coding of 'denial of object identity' and 'inability' was firmly established, and used by all subjects. 'Denial of happening of event' and 'denial of object function' continued to be used sparingly, and were used by CGK, HHC and LLY, and MHZ and WBH respectively.

\section{Individual developmental patterns}

The children who were sampled in at least three of the four stages (CGK, HHC, LLY, MHZ and WBH) provide some information about individual developmental patterns. Two of the children had steady growth patterns across the four Stages (HHC and WBH). Two children (LLY and CGK) had consistent use of negation throughout the developmental period with LLY having the highest rate of use of all five children, and CGK the lowest. The remaining child (MHZ) had a steady decline in the use of negation with increasing syntactic complexity. Thus there was no overall trend for the group, suggesting the need to consider individual differences, and indicating caution in drawing conclusions from a small sample of children.

Intersection of negative markers (form), semantic categories (content) and stage of development

Table 4 showed the negative markers used by each subject at each stage of development, in terms of the semantic categories encoded by each marker. For the five subjects sampled at Stage I only $m_{4}$ was used to encode Denial (and was encoded only by two subjects) whereas both Nonexistence and Rejection were encoded by $\operatorname{mou}_{5}$ and $\mathrm{m}_{4}$. At Stage II Denial was encoded by $m_{4}$ and $m e i_{6}$ (the latter by one subject only); Nonexistence and Rejection were both encoded by all three forms, $m_{0} u_{5}, m_{4}$ and $m e i_{6}$ (with the latter being used for Rejection by one subject only, but not the same subject who used $m e i_{6}$ for Denial). At Stage III Denial was encoded mostly by $m_{4}$ and $m_{0} u_{5}$ (the latter used by one subject only), and like Stage II, both Nonexistence and Rejection were encoded by all three forms, $m o u_{5}, m_{4}$ and $m e i_{6}$. Again the latter was used for Rejection by one subject only (and not the same subject as previously). At Stage IV, Denial was still encoded by $m_{4}$ and $m_{0} u_{5}$, Nonexistence was encoded by all three forms, and Rejection was encoded predominantly by $m_{4}$, with one child continuing to use $\operatorname{mou}_{5}$.

There was a steady use of $\mathrm{mou}_{5}$ and $m_{4}$ to encode Nonexistence across all four developmental stages, with the gradual addition of $m e i_{6}$ to encode Nonexistence (used by $50 \%$ of children at Stage II, 7 I \% of children at Stage III and $60 \%$ of children at Stage IV). Rejection was initially coded by $m_{4}$ and $\operatorname{mou}_{5}$ with a steady decrease of $\operatorname{mou}_{5}$ until only $m_{4}$ was used to encode Rejection (with the exception of one subject). Denial was initially encoded 
with $m_{4}$ only, and other forms were used by few children across the four stages. That is, MHZ used $m e i_{6}$ for Denial at Stage II, LTF used $m o u_{5}$ for Denial at Stage III and CGK and LLY used $m^{\circ} u_{5}$ for Denial at stage IV. It is worth noting that only CGK did not use $m^{2} i_{6}$ at all, however he was not the youngest subject, with his last sample taken at the age of $2 ; 8$, the same as MHZ and similar to $\operatorname{CCC~}(2 ; 10)$ and $\operatorname{CKT}(2 ; 5)$. In summary, the developmental pattern, distilled from group data was as shown in Table 7 .

TAB LE 7. Intersection of grammatical markers, semantic roles and stage of development

\begin{tabular}{lllll}
\hline $\begin{array}{l}\text { Grammatical } \\
\text { marker }\end{array}$ & Stage I & Stage II & Stage III & Stage IV \\
\hline mou $_{5}$ & $\begin{array}{l}\text { Nonexistence } \\
\text { Rejection }\end{array}$ & $\begin{array}{l}\text { Nonexistence } \\
\text { Rejection }\end{array}$ & $\begin{array}{l}\text { Nonexistence } \\
\text { Rejection }\end{array}$ & Nonexistence \\
$\mathrm{m}_{4}$ & Nonexistence & Nonexistence & Nonexistence & Nonexistence \\
& Rejection & Rejection & Rejection & Rejection \\
& Denial & Denial & Denial & Denial \\
mei $_{4}$ & - & Nonexistence & Nonexistence & Nonexistence \\
\hline
\end{tabular}

\section{DISCUSSION}

Frequency of occurrence of markers

The form $m_{4}$ was the most commonly occurring negative marker in early developmental Cantonese. The intersection of negative markers and semantic categories and the syntactic form of the markers may explain this finding. The marker $m_{4}$ could be used for all of the subordinate semantic categories. Therefore, the frequency of use of $m_{4}$ was higher than that of the other markers. The marker $\operatorname{mou}_{5}$ was the second most frequent in occurrence and served eight subordinate semantic categories. The third marker, mei $_{6}$ served five subordinate semantic categories. The more semantic categories a marker served, the more frequently the marker occurred within normal conversation and the higher the learnability of the form, such that $m_{4}$ comes at the foreground of representation within the negative system. Besides, as $m_{4}$ is the prefix of a word or a particle, it can combine with different words and particles to form negative verbs and adjectives (Matthews \& Yip, I994). When compared with the number of possible combinations of the three markers, $m_{4}$ is the most flexible.

The marker mai occurred only once for the meaning of negative imperative. This may be due to the role of this marker in Cantonese and sociolinguistic factors. The most important function of mai from the children's language samples was its role as a marker in a question. Although mai could serve to introduce negative commands, it is comparatively less common than $m_{4} h o u_{2}$ in Cantonese for the same meaning. As described by Matthews \& Yip ( I 994), 
both mai and $m_{4} h o u_{5}$ mean don't. The form $m_{4} h o u_{2}$ is commonly used to express don't as mai is an impolite form used mostly within peer groups. In the process of recording, children interacted with their parents, relatives and investigators and, because of politeness requirements and the social status of the children, they rarely produced this marker in their language. Besides, as observed from the adults' language samples from the corpus, the frequency of mai as a meaning of negative imperative is uncommon in adults too. Some of the parents and relatives of the children did not use this marker in their language. Therefore, the input frequency of mai is comparatively less than that of the other markers, perhaps providing another reason why mai is rare in all eight children's samples.

\section{Frequency of use of superordinate categories}

The most frequently used category was Nonexistence $(43 \%$ of all negative utterances) followed by Rejection $(32 \%)$ and Denial (25\%) (Table 5). Although the frequency of use of Nonexistence remained steady over the sampling period, the frequency of Rejection decreased as Denial increased. This relationship may reflect changes in cognitive or pragmatic abilities with increasing age, or it may reflect the type of competition among elements of a cognitive system described by van Geert ( I 993) whereby growth or increase in one element may result in a decline or decrease in another. As was noted in Table 5, negation was encoded most frequently at Stage III of development, with less frequent use at earlier and later stages of development, (Stage I $=435$ negative utterances of 7464 utterances, Stage II $=784$ negative utterances of 7308 utterances, Stage III $=903$ negative utterances of 8725 utterances and Stage IV $=562$ negative utterances of 5 I 22 utterances). This pattern is possibly reminiscent of an S-pattern of growth that has been identified previously in vocabulary development (Dromi, I986) although there is more drop off at the end of the sampling period than one would expect in a typical S-shaped pattern. Nonetheless, the rapid acceleration from Stage I to Stage II, the slower acceleration to Stage III and then the falling off of growth at Stage IV, perhaps as a trade-off with increasing syntactic ability, may reflect typical patterns of cognitive growth which include periods of variation in growth rate as well as variations in timing of growth spurts (van Geert, I 993).

Developmental order of the subordinate categories

The developmental order of the subordinate semantic categories can be explained in terms of children's cognitive development. For example, Nelson ( 1985 ) noted that children are initially aware of the existence of objects in their environment, but only later build concepts of event structure. This may explain why the semantic categories of 'nonexistence of object' and 'nonrecurrence of object' appear in the very early stages. The developmental 
order of 'nonoccurrence/nonrecurrence of event' would occur later, because children attend to objects before actions and events. This interaction between conceptual development and language development may be accounted for by the notion of minimal growth - that some conditions must exist before growth commences or is accelerated (van Geert, I 993). In this specific case of negation, the conceptual foundations of object permanence exist as conditions for encoding the language of 'nonexistence' and/or 'occurrence' before 'reoccurrence', and subsequently the concept of event knowledge must exist before children can encode language functions such as 'denial of happening of event'. Furthermore, the average age for comprehension of adjectives and object functions is $2 ; 0$ to $3 ; 6$ (Owens, I 988) so the acquisition of 'nonexistence of state' or 'quality of object', and 'denial of object function' is later in the sequence.

As noted above, developmental differences in the encoding of superordinate categories, and here subordinate categories, probably reflect cognitive and/or pragmatic advances with increasing age, not only increasing linguistic sophistication. For example, one might suppose that the ability to express simple 'occurrence of event' (e.g. ball bounce) would be substantially easier to encode than 'nonrecurrence of event' (not bounce now/again/yet) where an element of expectation is also encoded along with a linguistic marker of time. Expression of 'denial of object identity' and expression of 'denial of object function' may both require the child to contradict the adult, dependent on context. Encoding 'inability' requires that the child expresses ability to perform, for example, 'can jump' or 'can't jump' which may be a later cognitive development in terms of sense of identity than simple expressions of Nonexistence for example.

\section{Individual differences in the use of semantic categories}

The pattern of use of the superordinate semantic categories suggests that results from small-scale longitudinal studies be interpreted cautiously. While WBH had a clear, and expected developmental pattern of increasing use of all three semantic categories over time, he was the only child of the five children sampled at more than one data point to do so. HHC had a similar, though not identical pattern of development, with a steady use of Nonexistence from Stage I to Stage III and then a sharp increase in encoding at Stage IV. This same pattern applied to Rejection and Denial, although Denial was not used at all by HHC until Stage IV. Both LLY and CGK had consistent unchanging use of all three categories. LLY had high use of Nonexistence across the period but a low use of Rejection and a slightly higher use of Denial. CGK had very little encoding of negation overall. MHZ posed the greatest puzzle of all the children. He had a gradual reduction in the use of negation over time (as a function of all utterances in his samples). It is possible that changing pragmatic functions and discourse 
requirements resulted in this pattern, although this hypothesis can not be validated without a complete classification of all of his 5295 utterances.

\section{Sequence of emergence of markers and their semantic roles}

The sequence of emergence of $m o u_{5}=m_{4}>m e i_{6}$ in this study concurred with L. Lee's ( 1992) experimental study of comprehension with 27 children aged between $2 ; 6$ and 4;6. She attributed the developmental order to the development of cognitive ability and linguistic complexity. In this study, there was a relationship between the sequence of emergence of the form and the acquisition order of the semantic category. The earliest acquired semantic categories were Nonexistence and Rejection, both expressed by the markers $m o u_{5}$ and $m_{4}$ for most of the children. For the form $m e i_{6}$, the earliest meaning is nonoccurrence of event in most of the children. This suggests a tighter relationship between emergence order of the negative marker $m e i_{6}$ and semantic categories than that for mou $_{5}$ and $m_{4}$. The late emergence of $m e i_{6}$ may be related to cognitive development. The form $m e i_{6}$ is unique among all negative markers in that it carries a temporal concept of 'not yet complete'. Thus, children need to not only acquire the negative meaning and learn how to use it, but also need to acquire the temporal concept before they could correctly use the marker in their language. Therefore, the developmental order of $m e i_{6}$ is later than the other two markers.

\section{Inappropriate use of markers}

While children's use of the negative markers was mostly appropriate, there was some inappropriate usage of the negative markers in some of the utterances from the children's language samples. Inappropriate usage could be indicative of a period of transition between well-established and emerging markers. These transitional periods could further explain the developmental order of the negative markers. Most of the errors for $m_{4}$ were where the child used $m o u_{5}$ to substitute for $m_{4}$ in the utterance. In the following example, the child wanted to express the semantic meaning of negative volition. Native Cantonese speakers would answer this by a negative word that starts with the negative marker $m_{4}$, e.g. $m_{4} h o u_{2}$ or $m_{4} d a k_{1}$.

Example:

The investigator asks the child to remove the clothes from the washing machine after washing them.

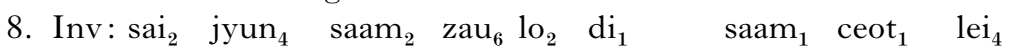
wash post- clothes then take classifier clothes remove sentenceverbal-

finalparticle particle (you) take the clothes out when the washing is finished 


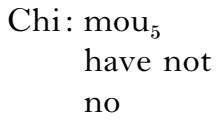

However, in the same conversation, the child used $m_{0} u_{5}$ for most negative utterances and showed some correct use of $m_{4}$ as well. These types of errors are distinguished from those where the more advanced form does not appear in the child's lexicon. For example, there were examples where a child used $m_{4}$ instead of $m e i_{6}$ in an utterance with no previous use of $m e i_{6}$ in his language sample. This may be because the negative marker $m e i_{6}$ was not yet established in the child's lexicon.

An interesting stereotypic use of a negative marker was seen in one child, who frequently produced $m_{4} h a i_{6}$ in his data. The child used this negative utterance to change the topic (e.g. the investigator asked him some questions but he wanted to talk about another topic) or to seek the attention of the adult. Most Cantonese speakers would not use a negative utterance to serve these two pragmatic functions. This is unusual both developmentally and in adult form. For example when the investigator was talking to the mother the child said:

9. Chi: $\mathrm{m}_{4}$ hai $_{6} \mathrm{aa}_{3}$

$$
\begin{aligned}
& \text { not be sentence final particle } \\
& \text { don't }
\end{aligned}
$$

This is an example of attention-seeking. This phenomenon was only present in Stage I and early Stage II of the child's data.

Overall, the acquisition trend of semantic categories in this study matched Bloom's (I970, г99 Ia) findings that Nonexistence preceded Rejection and Denial. A further finding was that two markers, $m o u_{5}$ and $m_{4}$ were used with equal facility at the earliest sampling periods, and $m e i_{6}$ emerged later.

\section{Further investigation}

This study focused on the analysis of verbal lexical negation only, but negation can be expressed by non-verbal expression (e.g. shaking head) and utterances without an overt negative marker, that is via suprasegmental features of an utterance. For example, vowel prolongation and rising tone of the last word of an utterance could signal negative meaning in Cantonese, however it is not yet known how these features operate in adult Cantonese. It may be useful to investigate these two areas to determine the semantics of negation in both adult language and early language development. Besides, negative utterances may serve different pragmatic intents, such as greeting and indirect request. However, the pragmatics of negation in Cantonese have not been studied. Furthermore, as the syntactic form of negation may affect the emergence of negative markers and semantic categories, a syntactic analysis would complement the findings of this study. 


\section{NEGATION IN DEVELOPMENTAL CANTONESE}

That is, it may be informative to track a child's use of negation within noun phrase and verb phrase structures as these increase in complexity over time.

\section{REFERENCES}

Bloom, L. ( 1970). Language development : form and function in emerging grammars. Cambridge: MIT Press.

Bloom, L. (I 991 I). Language development from two to three. Cambridge: C.U.P.

Bloom, L. (r $99 \mathrm{rb})$. On the acquisition of negation in Tamil and English. Fournal of Child Language $\mathbf{1 8}, 7$ I 5-16.

Bowerman, M. (I973). Early syntactic development: a cross-linguistic study with special reference to Finnish. London: Cambridge University Press.

Choi, S. (I 988). The semantic development of negation: a cross-linguistic longitudinal study. Fournal of Child Language 15, 5 I-3 1 .

Dromi, E. (I986). The on-word period as a stage in language development: quantitative and qualitative accounts. In I. Levin (ed.), Stage and structure : reopening the debate. Norwood, NJ : Albex

Drozd, K. F. (1995). Child English pre-sentential negation as metalinguistic exclamatory sentence negation. Fournal of Child Language 22(3), 538-610.

Lahey, M. (1988). Language disorders and language development. New York: Macmillan Publishing.

Lee, L. (1992). Understanding of negation in Cantonese-speaking children. Unpublished undergraduate dissertation, University of Hong Kong.

Lee, T. H-T. (1982). The development of negation in mandarin-speaking child. Language Learning and Communication, $\mathbf{I}(3), 269-8 \mathrm{I}$.

Lee, T. H-T., Wong, C. H., Leung, C. S., Man, P., Cheung, A., Szeto, K. \& Wong, C. SP. ( 1994$)$. The development of grammatical competence in Cantonese-speaking children, Report of RGC earmarked grant.

Matthews, S. \& Yip, V. (I994). Cantonese : a comprehensive grammar. London: Routledge.

McNeill, D. \& McNeill, N. B. (1968). What does a child mean when he says "No"?. In E. M. Zale (ed.), Proceedings of the conference on language and language behavior. New York: Appleton-Century-Crofts.

Miller, J. F. \& Chapman, R. S. (1993). SALT : systematic analysis of language transcripts (basic $S A L T$ programmes). Madison: University of Wisconsin-Madison.

Nelson, K. (1985). Making sense: the acquisition of shared meaning. New York: Academic Press.

Owens, R. E. (1988). Language development: an introduction. Columbus, OH: Charles E. Merrill.

Park, T-Z. (I979). Some facts on negation: Wode's four-stage developmental theory of negation revisited. Fournal of Child Language 6, I 47-5 I.

Vaidyanathan, R. (I99I). Development of forms and functions of negation in the early stages of language acquisition: a study in Tamil. Fournal of Child Language 18, 5 I-66.

van Geert, P. (I 993). A dynamic systems model of cognitive growth: competition and support under limited resource conditions. In L. B. Smith \& E. Thelen (eds), A dynamic systems approach to development : applications. Cambridge, MA: MIT Press.

Wode, H. (1976). Four early stages in the development of Li negation. Fournal of Child Language 4, 87-102.

Yip, M. (I 988). Negation in Cantonese as a lexical rule. The Bulletin of the Institute of History and Philology Academia Sinica LIX(II), 449-77. 